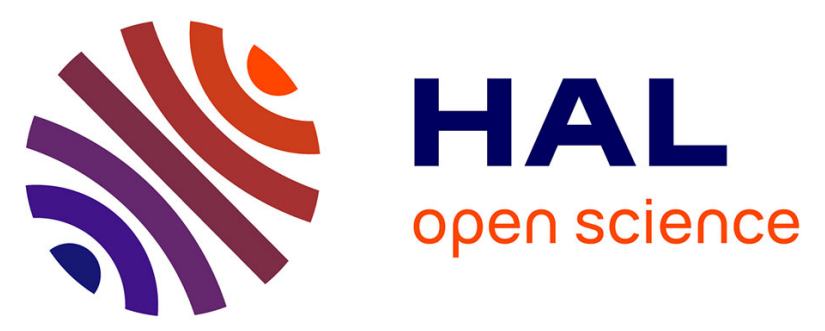

\title{
Impact of longitudinal exposure to mycophenolic acid on acute rejection in renal-transplant recipients using a joint modeling approach.
}

Zeinab Daher-Abdi, Marie Essig, Dimitris Rizopoulos, Yannick Le Meur, Aurélie Prémaud, Jean-Baptiste Woillard, Jean-Philippe Rerolle, Pierre

Marquet, Annick Rousseau

\section{To cite this version:}

Zeinab Daher-Abdi, Marie Essig, Dimitris Rizopoulos, Yannick Le Meur, Aurélie Prémaud, et al.. Impact of longitudinal exposure to mycophenolic acid on acute rejection in renal-transplant recipients using a joint modeling approach.. Pharmacological Research, 2013, 72, pp.52-60. 10.1016/j.phrs.2013.03.009 . inserm-00809389

\section{HAL Id: inserm-00809389 https://www.hal.inserm.fr/inserm-00809389}

Submitted on 9 Apr 2013

HAL is a multi-disciplinary open access archive for the deposit and dissemination of scientific research documents, whether they are published or not. The documents may come from teaching and research institutions in France or abroad, or from public or private research centers.
L'archive ouverte pluridisciplinaire HAL, est destinée au dépôt et à la diffusion de documents scientifiques de niveau recherche, publiés ou non, émanant des établissements d'enseignement et de recherche français ou étrangers, des laboratoires publics ou privés. 
Impact of longitudinal exposure to mycophenolic acid on acute rejection in renal-transplant recipients using a joint modeling approach

Z. Daher Abdi ${ }^{1,3}$, M. Essig ${ }^{1,2,3}$, D. Rizopoulos ${ }^{4}$, Y. Le Meur ${ }^{5}$, A. Prémaud ${ }^{1,3}$, J.B. Woillard ${ }^{1,3}$, J.P. Rérolle ${ }^{1,2}$, P. Marquet ${ }^{1,3,6}$, A. Rousseau ${ }^{1,3}$.

${ }^{1}$ Inserm, UMR-S850, Limoges, France; ${ }^{2}$ Department of Nephrology, Dialysis and Transplantations, University Hospital Limoges, France; ${ }^{3}$ University of Limoges, France;

${ }^{4}$ Department of Biostatistics, Erasmus Medical Center, Rotterdam, the Netherlands,

${ }^{5}$ Department of Nephrology, University Hospital, Brest, France, ${ }^{6}$ Department of Pharmacology and Toxicology, University Hospital Limoges, France.

Address correspondence to:

Annick Rousseau; Inserm UMR-S850, Faculty of Pharmacy,

2 Rue Dr Marcland

87025 Limoges cedex, France;

Phone : +33-555-43-58-95; Fax : +33-555-43-59-36

Email: annick.rousseau@unilim.fr

Abbreviations: AR: acute rejection; AUC: area under the plasma concentration vs. time curve; CC: concentration-controlled; CNI: calcineurin inhibitor; CSA: cyclosporine; FD: fixed-dose; HPLC: highperformance liquid chromatography; IMPDH II: Inosine 5' monophosphate dehydrogenase II; JM: joint model; MMF: mycophenolate mofetil; MPA: mycophenolic acid; PK, pharmacokinetic; PD: pharmacodynamic; RCT: randomized controlled trial; ROC: Receiver-operating characteristics; TDM: therapeutic drug monitoring. 


\section{ABSTRACT}

This study aimed to investigate the association between longitudinal exposure to mycophenolic acid (MPA) and acute rejection (AR) risk in the first year after renal transplantation, and to propose MPA exposure targets conditionally to this association. A joint model, adjusted for monitoring strategy (fixed-dose versus concentration-controlled) and recipient age, was developed; it combined a mixed-effects model to describe the whole pattern of MPA exposure (i.e. area under the concentration-time curve -AUC-) and a survival model. MPA AUC thresholds were determined using time-dependent Receiver-Operating Characteristics (ROC) curves. Data from 490 adult renal-transplant recipients, representative of the general population of adult renal-transplant patients (i.e. including patients considered at low immunological risk -enrolled in the OPERA trial- as well as second renal transplant and patients co-treated by either cyclosporine or tacrolimus), were analyzed. A significant association was found between the longitudinal exposure to MPA (MPA AUCs=f(t)) and AR $(\mathrm{p}=0.0081$ ), and validated by bootstrapping. A significant positive correlation was observed between time post-transplantation and ROC thresholds which increased in average from 35 $\mathrm{mg} . \mathrm{h} / \mathrm{L}$ in the first days to $41 \mathrm{mg} . \mathrm{h} / \mathrm{L}$ beyond six months post-transplantation ( $<<0.001$ ).

Using a new modeling approach which recognizes the repeated measures in a same patient, this study supports the association between MPA exposure and AR.

Key words: mycophenolic acid, renal-transplant recipients, longitudinal exposure, acute rejection, joint modeling, ROC thresholds. 


\section{Introduction}

Mycophenolate mofetil (MMF) is an ester prodrug of the immunosuppressant mycophenolic acid (MPA) indicated in combination with cyclosporine (CsA) or tacrolimus to prevent rejection following organ transplantation.

The role of therapeutic drug monitoring (TDM) for MPA is still debated by many physicians, and the controversies of its utility were recently discussed $(1,2)$.

Several observational studies comparing, over the first year post-transplantation, patients with and without T-cell mediated acute rejection (AR) found lower MPA inter-dose area under the plasma concentration vs. time curve (AUC) values in patients with AR (3-5). However, a few other observational studies did not detect such an association between MPA AUC and rejection (6-8). The association between MPA AUC and the risk of rejection has also been investigated in a few randomized controlled trials (RCTs), providing a higher level of evidence than observational retrospective studies $(9,10)$. However, their results were also discordant. The Randomized Concentration Control Trial -RCCT-study (11) compared, in renal-transplant patients co-treated with MMF and CsA, the incidence of AR in three patient groups assigned to low (MPA $\left.\mathrm{AUC}_{0-12 \mathrm{~h}}<30 \mathrm{mg} \cdot \mathrm{h} / \mathrm{L}\right)$, intermediate $\left(\mathrm{AUC}_{0-12 \mathrm{~h}}=30\right.$ to 60 mg.h/L) or high $\left(\mathrm{AUC}_{0-12 \mathrm{~h}}>60 \mathrm{mg} . \mathrm{h} / \mathrm{L}\right) \mathrm{MPA}$ exposure. This trial showed a significantly higher incidence of AR in the low MPA exposure group and an increased incidence of adverse effects with no gain in efficacy in the higher exposure group, as compared to the intermediate group. Consequently, a 30-60 mg.h/L target window was proposed for MPA $\mathrm{AUC}_{0-12 \mathrm{~h}}$. Two prospective randomized trials (the so-called APOMYGRE (12) and FDCC (13) studies) further compared the incidence of AR in patients receiving, over the first year post-transplantation, either a fixed-dose (FD) regimen of MMF (1g twice daily in adults) or a concentration-controlled (CC) regimen adjusted to achieve a target MPA $\mathrm{AUC}_{0-12 \mathrm{~h}}$ (of 45 and 40 mg.h/L in FDCC and APOMYGRE, respectively). The FDCC study (13) enrolled adult 
and pediatric patients co-treated with CsA or tacrolimus, allowed for different analytical methods for MPA measurement, employed multiple linear regression for AUC estimation and let clinicians calculate the adjusted doses. It did not show any difference between the two randomization groups. However, retrospective analysis of the concentration-effect data showed a significant association between early MPA AUC (i.e., on day 3) and biopsy proven AR occurring in the first month, as well as in the first year post-transplantation. More specifically, a recent re-analysis of the FDCC data showed that this statistical association was only true in high-risk patients (i.e., patients with one or more of the following characteristics: delayed graft function, second or third transplantation, panel reactive antibodies $>15 \%$, four or more human leukocyte antigen mismatches, or of black race) (14). In the APOMYGRE study (12), only adult patients co-treated with CsA were enrolled, MPA measurements were performed by high-performance liquid chromatography (HPLC), AUC were calculated by Bayesian estimation (15) and dose adjustments were computer-assisted. The median MPA AUCs were higher in the CC group at day 14 and at month 1, a time at which significantly more patients had AUC values above the target of $40 \mathrm{mg} . \mathrm{h} / \mathrm{L}$. A significantly higher incidence of AR was found in the FD group compared to the CC group (Cox model, $\mathrm{p}=0.017$ ). Interestingly, there was no AR episode associated with an AUC $>45 \mathrm{mg} . \mathrm{h} / \mathrm{L}$ in the first three months post-transplantation. The last randomized fixed-dose $v s$. concentration-controlled trial in patients with a low immunologic risk (OPERA) (16) failed to demonstrate the benefit of MPA TDM: at 12 months, the overall rejection rates were similar in both groups.

One explanation of these discrepant results might be the insufficient statistical power of some of these RCTs. As we previously highlighted (17), the feasibility of such a study depends upon: (i) compliance with the pharmacokinetic sampling time-windows; (ii) use of relevant tools for accurate drug exposure estimation and dose adjustment calculation; and (iii) good compliance of the physicians with regard to the recommended doses. One of the problems 
with the FDCC trial (13) was probably that the proposed changes in MMF dose were not always appropriate, and were not performed in more than half of the cases.

Anyway, several recent consensus conferences (18-20) have recommended MMF monitoring based on MPA AUC in renal-transplant patients, mainly to overcome the problems of interpatient variability and time-dependent variations of MPA pharmacokinetics. Currently, MPA AUC is repeatedly measured in quite a number of transplantation centers (21).

No retrospective study dealing with MMF has taken into account the drug exposure profiles over time in order to analyze the longitudinal exposure/efficacy relationship and determine optimized exposure target values for TDM. The so-called "joint" or "time-to-event" models can now be used to conduct such pharmacokinetic/pharmacodynamic (PK/PD) studies. These models were recently proposed in the biostatistics area (22-25) to analyze simultaneously a longitudinal outcome, such as the repeated measurement of a biomarker (e.g., the MPA AUC measured at different times after transplantation), and a survival outcome which is the time to an event of interest (e.g., AR). At this time, only one study dealing with an immunosuppressive drug (Belatacept) has reported a joint model to analyze the relationship between time-varying exposure and AR; but no significant association was found (26). Additionally, receiver-operating characteristics (ROC) curves specifically adapted to joint models have also been developed and validated; this allows calculating time-dependent threshold values for a time-dependent explanatory variable (27).

The aims of the present study were to: (i) analyze the relationship between longitudinal exposure to MPA and AR in the first year following renal transplantation using a joint model; and (ii) to determine time-dependent MPA AUC thresholds in order to minimize the risk of rejection. 


\section{Materials and methods}

\subsection{Patients and treatment}

Data were collected from the databases of two multicenter, randomized clinical trials intended to investigate the clinical impact of MMF TDM in renal-transplant recipients, namely APOMYGRE (NCT0019967) and OPERA, and from adult renal-transplant recipients transplanted between 2007 and 2011 and routinely followed up at Limoges University Hospital. The trials complied with the Declaration of Helsinki. APOMYGRE was approved by the regional ethics committee of Limoges, France; OPERA was approved by the Independent Ethics Committee and by the relevant authorities (EUDRACT 2006-000352-41). All patients were followed during the first 12 months post-transplantation (Table 1). The different immunosuppressive regimens employed are reported in Table 2. In APOMYGRE and OPERA studies, patients were randomly divided (1:1) into two groups to receive concentration-controlled (CC) or fixed-dose (FD) of MMF. All patients received antibody induction therapy (basiliximab, daclizumab, or thymoglobuline) in conjunction with dual or triple maintenance therapy consisting in a starting dose of $1 \mathrm{~g}$ MMF twice daily associated to a calcineurin inhibitor (CNI) (i.e., CsA for APOMYGRE and OPERA patients as well as for 41 routinely followed patients or tacrolimus for 100 routinely followed patients) and/or corticosteroids. All patients enrolled in OPERA were considered at low immunological risk.

\subsection{Study endpoints}

The joint models were used to model a longitudinal explanatory variable and a time-to-event explained process, simultaneously. Herein, the two endpoints considered were: (i) repeated measurements of MPA AUC within the first year post-transplantation; and (ii) AR episodes diagnosed in the first year post-transplantation.

MPA was measured by high-performance liquid chromatography (HPLC) with an ultraviolet detector. MPA AUC values had been previously estimated in all the patients using the same 
validated Bayesian estimators based on a three-point sampling strategy (20 min, $1 \mathrm{~h}$ and $3 \mathrm{~h}$ post-dose) (15). MPA AUC values were studied for each patient at different time periods within the first year post-transplantation (the visit times planned in each study are reported in Table 1) except for 7 patients who experienced AR within the first month post-transplantation (i.e 2, 1 and 4 patients with AR around W1, W2 and M1, respectively). For these 7 patients for whom a single MPA AUC measurement was available, the single observed MPA AUC was duplicated one day after in order to keep these patients in the analysis. On the other hand, patients, who did not experience AR and with a single available MPA AUC value, were excluded from the analysis (i.e., 26 patients from the OPERA study and 2 patients from the APOMYGRE trial). In total, 221 patients included in OPERA, 128 in APOMYGRE and 141 patients routinely followed at Limoges were studied herein. Among these 490 MPA AUC trajectories provided, 56 were made up of only two MPA AUC values due to either occurrence of AR within the three first months post-transplantation $(n=26)$ or non-compliance with the schedule of measurement of MPA AUC $(n=30)$. In this later situation, patients were censored at the last examination time.

MPA exposure was characterized by a wide inter-subject variability over time; coefficients of variation for MPA AUC calculated at each post-transplantation period ranged from $42.7 \%$ to 45\%. The median MPA AUC (as well as the AUC/Dose ratio) increased gradually over the first year post-transplantation, from $33.2 \mathrm{mg} . \mathrm{h} / \mathrm{L}(0.014 \mathrm{~h} / \mathrm{L}$ for the AUC/Dose ratio) in the first weeks after transplantation, up to approximately $40 \mathrm{mg} \cdot \mathrm{h} / \mathrm{L}(0.02 \mathrm{~h} / \mathrm{L}$ for the AUC/Dose ratio) (Figure 1).

The AR event was diagnosed histologically on the renal biopsy. Renal biopsies were either performed as planned in the clinical trial or in the routine follow-up (protocol biopsies), or because of a clinical suspicion of AR (biopsies for cause). Biopsy proven AR was graded according to the Banff classification (28). Fifty five out of 490 patients experienced an AR 
episode in the first year post-transplantation. All were proven by histological reading of the renal biopsy except three (who were included in the APOMYGRE study) due to coadministration of anticoagulants which is a contra-indication.

\subsection{Modeling framework}

Figure 2 summarizes the important steps taken in the modeling framework which are described here.

\subsubsection{Development of a joint model between longitudinal MPA exposure and the risk of AR}

A brief technical specification of the joint models for longitudinal and survival data that we employed is presented in the Supplementary Material and Methods online, but the intention behind it can be described with the following three-step procedure.

In the first step, the individual trajectories of MPA AUC time-course obtained from the repeated estimates of AUCs collected in the first year post-transplantation (i.e., the longitudinal explanatory variable) are fitted using a mixed-effects model. Time was tested as a fixed-effect variable. Random effects were used to describe the inter-patient variability.

In the second step, rejection-free survival was studied using a time-dependent relative risk model with a Weibull baseline risk function. As the incidence of AR is known to decrease with time, the Weibull survival distribution was assessed to describe the time-dependent decrease in the hazard function (29).

The recipient age, the associated CNI, the "study" provenance (i.e., APOMYGRE/OPERA/ routinely followed patients) and the MMF dose-adjustment (DA) strategy used (namely FD and $\mathrm{CC}$ ) were tested as covariates both in the mixed-effects sub-model (which describes the trajectories of MPA AUC) as well as in the survival sub-model. A covariate was retained in the model if its inclusion improved the log-likelihood significantly $(\mathrm{p}<0.05)$.

In the third step, the mixed-effects model selected to describe the time course of MPA AUC was incorporated in the survival model. The resulting joint model allowed measuring the 
strength of the association between MPA longitudinal exposure and the hazard for AR. The goodness-of-fit of the final joint model was checked using classically recommended diagnostic plots based on: (i) the marginal and subject-specific residuals for the longitudinal outcome; and (ii) the martingale and Cox-Snell residuals for the time-to-event outcome. The Cox-Snell residuals were calculated as the value of the cumulative risk function evaluated at the times when the event occurred. The Cox-Snell residuals plot is expected to have a unit exponential distribution (30). The software implementation of these joint models is the JM-Rpackage described by Rizopoulos et al (22) .

\subsubsection{Internal model validation}

The accuracy and robustness of the joint model were assessed by an internal validation, using a non-parametric bootstrap method. Briefly, 300 bootstrap sets were obtained by resampling from the original dataset, each providing estimates of model parameters. The small number of bootstrap datasets used is due to long computational times. The mean and $95 \%$ confidence interval values of each model parameter estimated from the 300 bootstrap sets were compared to the corresponding parameters obtained with the original dataset. This procedure was performed using the $\mathrm{R}$ software version 2.13.0 ( $\mathrm{R}$ foundation for statistical computing, http://www.r-project.org).

\subsubsection{Determination of time-dependent targets of MPA exposure for individual dose} adjustment.

This step aims to determine the target exposure levels minimizing the risk of AR.

We estimated time-dependent thresholds (i.e., time-varying cut-offs) of MPA exposure using time-dependent ROC curves adapted to a joint modeling framework (27). Traditional ROC analysis assumes that the explanatory variable does not change over time, which is the case when its measurement is performed once, at the time of diagnostic. Herein, the exposure to MPA varied over time and AR could occur during the course of the patient follow-up. The 
time-dependent ROC curves used herein allowed the determination of threshold values that evolve over time. Thus, a different MPA AUC threshold for each post-transplantation studied period (days 7-14 and months 1, 3, and 6 post-transplantation) was determined by taking into account the shape of the MPA AUC time patterns. The 300 bootstrap samples used for the internal model validation were also used to determine the non-parametric $95 \%$ intervals of the ROC thresholds (defined by the $2.5^{\text {th }}$ and $97.5^{\text {th }}$ percentiles of the thresholds).

\section{Results}

\subsection{Joint model for longitudinal MPA exposure and the risk of $A R$ in the training dataset.}

A polynomial function with a quadratic term was selected to describe the trajectories of MPA AUCs over time. A significant improvement was obtained by inclusion of the MMF doseadjustment strategy as covariate in the model (i.e., fixed-dose $v s$ concentration-controlled). The survival model was adjusted to the recipient age. The final longitudinal and survival submodels obtained were expressed in the equations (1) and (2), respectively.

(1) $\mathrm{Y}_{\mathrm{i}}\left(\mathrm{t}_{\mathrm{ij}}\right)=\boldsymbol{\beta}_{\mathbf{0}}+\boldsymbol{\beta}_{1} \times \mathrm{tij}+\boldsymbol{\beta}_{\mathbf{2}} \times \mathrm{t}_{\mathrm{ij}}^{2}+\boldsymbol{\beta}_{3} \times \mathrm{DA}+\mathbf{D}_{\mathbf{0}}+\mathbf{D}_{\mathbf{1}} \times \mathrm{t}_{\mathrm{ij}}+\mathbf{D}_{\mathbf{2}} \times \mathrm{DA}+\varepsilon_{\mathrm{i}}(\mathrm{t})$,

(2) $h_{i}\left(t \mid M_{i}(t)\right)=\mathbf{h}_{0}(t) \exp [\boldsymbol{\gamma}($ Age $)+\boldsymbol{\alpha}(\operatorname{MPA}$ AUC $(t))]$

Where:

in (1): $\beta_{0}, \beta_{1}$, and $\beta_{2}$ represent the mean regression coefficients estimating respectively the intercept, the linear and the quadratic terms of the polynomial equation of time; $\beta_{3}$ is the mean regression coefficient corresponding to the effect due to the MMF dose-adjustment (DA) strategy; D0 and D1 the random effects for intercept and linear term of time; D2 the random effect for the MMF DA strategy; $\varepsilon_{i}(t)$ the measurement errors of the longitudinal MPA exposure; 
in (2): $\gamma$ represents the mean regression coefficients corresponding to the explanatory variable "recipient age" in the hazard sub-model; and $\alpha$ is the coefficient measuring the association between longitudinal MPA exposure described by the mixed-effects model (MPA AUC (t)) and the hazard of AR at time $\mathrm{t}$.

The joint model obtained by combining the mixed-effects sub-model (equation 1) and the survival sub-model (equation 2) showed a significant association between the MPA AUC trajectories and AR in the first year post-transplantation $(\alpha=-0.044, p=0.0081)$. The risk of AR decreases with increasing MPA AUC value $(\alpha<0)$. The parameter estimates of the final joint model are summarized in Table 3.

The residual plots, performed to check the goodness of fit of the joint model, are illustrated in Figure 3. The fitted loess curves in the plots of the standardized marginal and subject-specific residuals did not show any systematic error trend. Also, no systematic error trend was observed for the martingale residuals, indicating that the formulation chosen to describe the MPA AUC profiles was appropriate (30). Moreover, the unit exponential distribution seemed to be very close to the Kaplan-Meier estimates of the Cox-Snell residuals, and well within the 95\% confidence interval (CI), indicating a good fitting of the survival part of the joint model. Two hundred eighty seven out of 300 runs converged successfully in the bootstrap analysis. The mean bootstrap parameter estimates and their 95\% confidence intervals are shown in Table 3. The mean of the bootstrap parameters was not statistically different from the parameter estimates based on the original dataset (Table 3).

\subsection{ROC analysis and time-dependent targets of MPA exposure using the final joint model}

The determined thresholds (with ROC AUC $\geq 0.55$ throughout the study period) increased significantly with time post-transplantation: from $35 \mathrm{mg} . \mathrm{h} / \mathrm{L}\left(2.5^{\text {th }}-97.5^{\text {th }}\right.$ percentiles obtained by bootstrap: $31-39 \mathrm{mg} . \mathrm{h} / \mathrm{L})$ around week $2,37 \mathrm{mg} \cdot \mathrm{h} / \mathrm{L}\left(2.5^{\text {th }}-97.5^{\text {th }}\right.$ percentiles : $33-41$ 
mg.h/L $)$ around month $1,40 \mathrm{mg} . \mathrm{h} / \mathrm{L}\left(2.5^{\text {th }}-97.5^{\text {th }}\right.$ percentiles: $\left.37-43 \mathrm{mg} . \mathrm{h} / \mathrm{L}\right)$ around month 3 , to $41 \mathrm{mg} . \mathrm{h} / \mathrm{L}\left(2.5^{\text {th }}-97.5^{\text {th }}\right.$ percentiles: $\left.36-43 \mathrm{mg} . \mathrm{h} / \mathrm{L}\right)$ after month 6 ( quadratic correlation $\mathrm{r}^{2}=$ $0.53, \mathrm{p}<0.001)$

Figure 4 shows the distribution of MPA AUCs observed in patients exhibiting and not exhibiting acute rejection superimposed with the proposed ROC thresholds (and their 95\% interval based on the $2.5^{\text {th }}$ and $97.5^{\text {th }}$ percentiles obtained using the bootstrap samples). The mean MPA AUCs in patients who did not experience AR were either included in this 95\% interval of the ROC thresholds or above the upper limit of this interval (Figure 4a). All the patients with AR had one or several MPA AUC(s) below the ROC threshold(s) during the exposure follow-up (i.e. before rejection). In most of the patients, the MPA AUC observed at the time of diagnosis of AR was lower than the threshold proposed at the same posttransplantation period in this study. Certain patients, however, had a MPA AUC above the threshold at time of diagnosis with AR but they had had low (even very low in some patients) MPA AUCs before the rejection as shown in figures 4b, 4c, 4d and 4e. Figure 5 shows typical profiles of MPA AUC-time profiles for these two kinds of patients who experienced rejection.

\section{Discussion}

Our study showed, in a large group of patients, a significant association between longitudinal exposure to MPA and the incidence of AR over the first year post-transplantation.

Previously published studies dealing with the relationship between MPA exposure and AR were based on between-group comparisons of mean exposure at a single post-transplantation time $(3,4,6)$. This method is not adapted to analyze a longitudinal exposure/efficacy relationship and lacks statistical power. A single AUC measurement is unable to reflect drug exposure over time as it does not take into account any within-patient variability associated with the longitudinal evolution of MPA exposure. Moreover, in some studies, MPA exposure was retrospectively compared at different post-transplantation times between patients who 
had or had not experienced AR in the months which followed $(5,31,32)$. However, in general no correction of the significance level for multiple comparisons was done; consequently the level of significance of the multiple comparisons was probably often overestimated. On the other hand, the randomized, controlled FD vs. CC trials were designed to investigate the clinical impact of MMF TDM and not the exposure/rejection relationship $(11-13,16)$.

Joint models offer an efficient method to quantify the risk of AR linked to a longitudinal marker of exposure such as the MPA AUCs. Indeed, by relying on the individual longitudinal exposure, these models account for the intra-patient pharmacokinetic variability (22-25). In this study, the joint model used included a polynomial mixed-effects sub-model to describe the longitudinal evolution of MPA AUCs and a Weibull survival sub-model for the hazard of AR. The model was improved by introducing the MMF dose-adjustment (DA) strategy and the recipient age as covariates in the longitudinal and survival sub-models respectively. We found a significant association between MPA exposure and AR in the first year after transplantation. The classic diagnostic plots used (30) revealed that this model had no major bias and fitted the survival data well. Interestingly, the association between MPA exposure and AR remained statistically significant $(\mathrm{p}=0.0466)$ when the re-transplanted patients $(\mathrm{n}=14)$ were excluded from the database. This shows that the association also exists when only de novo renal-transplant patients are considered. Additionally, the database was re-analyzed after exclusion of the patients included in OPERA which was a study done in a population at low risk for acute rejection. The incidence of acute rejection was lower in OPERA than in the rest of the database (15/221 patients experienced acute rejection in OPERA versus 39/269 in the rest of the database, $\mathrm{p}=0.011$ ). In this complementary analysis, the association between MPA AUC and acute rejection remained significant $(\mathrm{p}=0.0359)$ in a joint model adjusted for the MMF dose-adjustment strategy, recipient age and co-administered CNI (i.e. cyclosporine or tacrolimus). Of note, in the database obtained after exclusion of the data of OPERA, $37 \%$ of 
the patients were co-treated by tacrolimus (against only $20 \%$ in the full database), this explains why the co-treatment becomes a significant covariate.

The joint model developed in the full database was used to determine MPA exposure-efficacy thresholds based on time-dependent ROC curves (30). The mean exposure targets obtained increased slightly from $35 \mathrm{mg} . \mathrm{h} / \mathrm{L}$ in the first days to $41 \mathrm{mg} . \mathrm{h} / \mathrm{L}$ beyond six months posttransplantation. As shown in figure $4 \mathrm{~b}, 4 \mathrm{c}, 4 \mathrm{~d}$ and $4 \mathrm{e}$, most of the patients (43/55) who experienced acute rejection had been under-exposed either at time of rejection or before.

Van Gelder et al (14) previously showed a significant association between rejection and a measure of previous exposure (i.e. between the early MPA exposure (day 3) and the incidence of acute rejection in the first month and in the entire first year after renal transplantation). This observation suggests an increased risk of acute rejection in patients with underexposed periods. Non-adherence could be responsible for such underexposed periods.

Among the 12 other patients (12/55) with rejection, 4 patients missed some visits and the follow-up of their exposure was interrupted far before rejection. Therefore, the value of their last measured AUC (above the threshold) could not reliably reflect the exposure at the time of AR diagnosis. Finally, only 8 patients experienced rejection (1 at M1, 5 at M3 and 2 after M6) despite of a full MPA AUC profile over the thresholds.

The thresholds proposed for MPA AUC are in accordance with targets derived from RCTT (11) and chosen for APOMYGRE and FDCC $(12,13)$. For instance, in the APOMYGRE study, in the first three months post-transplantation, no AR occurred when the AUC nearest to the event was $>45 \mathrm{mg} . \mathrm{h} / \mathrm{L}$. The proposed thresholds herein can be interpreted in terms of a rejection risk factor. Patients present an increased risk of rejection if their MPA exposure is lower than the proposed threshold. The proposed cut-offs are minimum exposure levels to reduce the risk of AR, but a slightly higher threshold (e.g., $\geq 45 \mathrm{mg} . \mathrm{h} / \mathrm{L}$ instead of $41 \mathrm{mg} . \mathrm{h} / \mathrm{L}$ ) 
can be chosen in order to benefit from a secure exposure window and to favor the specificity of the exposure marker.

The increase over time of the ROC thresholds obtained in the joint model is the reflect of a dual reality: the gradual increase of the MPA exposure observed during the first weeks posttransplantation and the decrease over time of the target exposure of calcineurin inhibitors coadministered. On one hand, the AUC/dose ratio increased over time (Figure 1b) and concentration increase can occur despite dose-reduction. The time-dependent changes in MPA pharmacokinetics have been previously described. Shaw et al concluded that they result in at least a $30 \%$ to $50 \%$ increase in $\mathrm{AUC}_{0.12 \mathrm{~h}}$ during the first weeks after transplantation (33). Van Hest et al (34) found that the time-dependent change of exposure to MPA is caused by decreasing apparent clearance of MPA, due to a combination of improving creatinine clearance, increasing albumin, increasing haemoglobin and decreasing CsA predose concentrations during the first 6 months after transplantation. On the other hand, in the present study, as recommended, the shorter the interval after transplantation, the higher the target concentrations used for cyclosporine (35) and tacrolimus (36) were. This should help justify the use of lower target MPA exposures to adjust the immunosuppression level.

According to the MPA thresholds proposed in our study, more than half of the patients were underexposed in the very first weeks post-transplantation (e.g., 61.4\% of AUCs were less than $30 \mathrm{mg} . \mathrm{h} / \mathrm{L}$ at week 2). This result is in accordance with previous studies $(12,14)$. Interestingly, in the CC sub-group, patients achieved the therapeutic target exposure faster than in the FD sub-group: only $30.4 \%$ had a MPA exposure less than $30 \mathrm{mg} . \mathrm{h} / \mathrm{L}$ at week 2 . However, the proportion of underexposed patients in both sub-groups decreased over time: $30.4 \%$ and $28.9 \%$ had an MPA AUC $<30 \mathrm{mg} \cdot \mathrm{h} / \mathrm{L}$ at or after 3 months post-transplantation in the FD and CC groups, respectively. In fact, after 3 months, patients were more likely to achieve an adequate MPA AUC, i.e. > $40 \mathrm{mg} \cdot \mathrm{h} / \mathrm{L}$. 
The present work provides strong new arguments in favor of a relationship between the MPA exposure level and the occurrence of AR in the first year after renal transplantation. However, this study has some limitations. First, the longitudinal exposure level to the co-administered CNI was not taken into account in the model while the exposure level to CsA or tacrolimus is also associated to the rejection risk (37-39). It was not possible in the 'JM' R-Package to investigate simultaneously the association between the longitudinal evolution of two quantitative variables and the onset of an event. However, the CsA and tacrolimus doses were individually adjusted to reach standardized target levels. Whatever the post-transplantation period studied (i.e. CsA: $\leq \mathrm{M} 1$, M2-M3, M4-M6, M7-M12; and for Tacrolimus: $\leq \mathrm{M} 1$; > M1) there was no significant difference between the 2-h post-dose cyclosporine mean concentrations or the trough tacrolimus mean concentrations obtained in patients with and without AR (t-test). Secondly, the joint model developed herein cannot be used for dynamic, subject-specific predictions of AR because the MPA exposure alone cannot predict the occurrence of an AR episode. Other factors than the exposure to immunosuppressive drugs have been shown to be associated with an alteration of the risk of AR, including delayed graft function (40), immunologic risks $(41,42)$, and polymorphisms in Inosine 5' monophosphate dehydrogenase II (IMPDH II), a target protein of MPA (43). Thus in the OPERA trial, which enrolled low immunological risk patients (defined as receiving a primary renal-transplant from a deceased or living donor with a panel reactive antibody level of $0 \%$ and a cold ischemia time less than or equal to $36 \mathrm{~h}$ ) the frequency of AR was rather low (16).

Joint models allowed herein a novel insight into understanding the impact of the (longitudinal) MPA exposure on rejection risk in renal transplantation. Such joint models are powerful tools for survival analysis when a time-dependent explanatory variable is measured intermittently. These joint models open new avenues of research for new mechanistic pharmacodynamics approaches. 
In summary, the association between MPA exposure and AR in renal-transplant recipients was investigated in this study using a new statistical approach dedicated to the study of relationships between the evolution of a quantitative variable and the onset of an event. Using this new modeling approach based on joint models, we clearly demonstrated a significant relationship between MPA exposure and AR. The suboptimal statistics used in previous studies may explain the discrepant results which were reported. Moreover, the minimal MPA exposure thresholds found in the present study confirm the targets of MPA exposure chosen in recent randomized, comparative clinical trials, as well as the therapeutic window recommended in the last consensus conference on MMF monitoring (18).

\section{Conflicts of interest/ Disclosure}

The authors of this manuscript have conflicts of interest to disclose. This study is based on data issued from clinical trials financially supported or sponsored by Roche France.

Some of the authors have also received research funds or have had research contracts from Astellas, Novartis, Pfizer and BMS. Dr Pierre Marquet is a consultant for Roche France and has received speaking fees and invitations to meetings from Astellas, Novartis and Pfizer. Dr Yannick Le Meur has received research grants and/or consultancy fees from Novartis, Roche, and Genzyme.

\section{Acknowledgments}

This study was funded by INSERM.

It is based on the databases of clinical trials funded by: the Regional Clinical Research Program of Limoges University Hospital; the French Drug Agency; the French South-West inter-regional program for clinical research; and Roche France. 
The authors gratefully thank Elisa Munteanu, Hélène Roussel and Fabrice Béavogui, for their excellent technical assistance, and Lynn Carr for her complete English and grammatical review of this paper. 


\section{References}

[1] Van Gelder T. Therapeutic drug monitoring for mycophenolic acid is value for (little) money. Clin Pharmacol Ther 2011;90(2):203-4.

[2] Byrne R, Yost SE, Kaplan B. Mycophenolate mofetil monitoring: is there evidence that it can improve outcomes? Clin Pharmacol Ther 2011;90(2):204-6.

[3] Pillans PI, Rigby RJ, Kubler P, Willis C, Salm P, Tett SE, et al. A retrospective analysis of mycophenolic acid and cyclosporin concentrations with acute rejection in renal transplant recipients. Clin Biochem 2001;34(1):77-81.

[4] Okamoto M, Wakabayashi Y, Higuchi A, Kadotani Y, Ogino S, Ushigome H, et al. Therapeutic drug monitoring of mycophenolic acid in renal transplant recipients. Transplant Proc 2005;37(2):859-60.

[5] Pawinski T, Durlik M, Szlaska I, Urbanowicz A, Majchrnak J, Gralak B. Comparison of mycophenolic acid pharmacokinetic parameters in kidney transplant patients within the first 3 months post-transplant. J Clin Pharm Ther 2006;31(1):27-34.

[6] Satoh S, Tada H, Murakami M, Tsuchiya N, Inoue T, Togashi H, et al. The influence of mycophenolate mofetil versus azathioprine and mycophenolic acid pharmacokinetics on the incidence of acute rejection and infectious complications after renal transplantation. Transplant Proc 2005;37(4):1751-3.

[7] Atcheson BA, Taylor PJ, Mudge DW, Johnson DW, Hawley CM, Campbell SB, et al. Mycophenolic acid pharmacokinetics and related outcomes early after renal transplant. $\mathrm{Br} \mathbf{J}$ Clin Pharmacol 2005;59(3):271-80.

[8] Kuypers DRJ, Claes K, Evenepoel P, Maes B, Vanrenterghem Y. Clinical efficacy and toxicity profile of tacrolimus and mycophenolic acid in relation to combined long-term pharmacokinetics in de novo renal allograft recipients. Clin Pharmacol Ther 2004;75(5):434-47.

[9] Benson K, Hartz AJ. A comparison of observational studies and randomized, controlled trials. N Engl J Med 2000;342(25):1878-86.

[10] Meakins JL. Innovation in surgery: the rules of evidence. Am J Surg 2002;183(4):399-405.

[11] Van Gelder T, Hilbrands LB, Vanrenterghem Y, Weimar W, De Fijter JW, Squifflet JP, et al. A randomized double-blind, multicenter plasma concentration controlled study of the safety and efficacy of oral mycophenolate mofetil for the prevention of acute rejection after kidney transplantation. Transplantation 1999;68(2):261-6.

[12] Le Meur Y, Büchler M, Thierry A, Caillard S, Villemain F, Lavaud S, et al. Individualized mycophenolate mofetil dosing based on drug exposure significantly improves patient outcomes after renal transplantation. Am J Transplant 2007;7(11):2496-503. 
[13] Van Gelder T, Silva HT, De Fijter JW, Budde K, Kuypers D, Tyden G, et al. Comparing mycophenolate mofetil regimens for de novo renal transplant recipients: the fixed-dose concentration-controlled trial. Transplantation 2008;86(8):1043-51.

[14] Van Gelder T, Tedesco Silva H, De Fijter JW, Budde K, Kuypers D, Arns W, et al. Renal transplant patients at high risk of acute rejection benefit from adequate exposure to mycophenolic acid. Transplantation 2010;89(5):595-9.

[15] Prémaud A, Le Meur Y, Debord J, Szelag J-C, Rousseau A, Hoizey G, et al. Maximum a posteriori bayesian estimation of mycophenolic acid pharmacokinetics in renal transplant recipients at different postgrafting periods. Ther Drug Monit 2005;27(3):354-61.

[16] Le Meur Y, Thierry A, Glowacki F, Rerolle J-P, Garrigue V, Ouali N, et al. Early steroid withdrawal and optimization of mycophenolic acid exposure in kidney transplant recipients receiving mycophenolate mofetil. Transplantation 2011;92(11):1244-51.

[17] Prémaud A, Rousseau A, Le Meur Y, Venisse N, Loichot C, Turcant A, et al. Feasibility of, and critical paths for mycophenolate mofetil Bayesian dose adjustment: pharmacological re-appraisal of a concentration-controlled versus fixed-dose trial in renal transplant recipients. Pharmacol Res 2010;61(2):167-74.

[18] Le Meur Y, Borrows R, Pescovitz MD, Budde K, Grinyo J, Bloom R, et al. Therapeutic drug monitoring of mycophenolates in kidney transplantation: report of The Transplantation Society consensus meeting. Transplant Rev (Orlando) 2011;25(2):58-64.

[19] Kuypers DRJ, Le Meur Y, Cantarovich M, Tredger MJ, Tett SE, Cattaneo D, et al. Consensus report on therapeutic drug monitoring of mycophenolic acid in solid organ transplantation. Clin J Am Soc Nephrol 2010;5(2):341-58.

[20] Shaw LM, Sollinger HW, Halloran P, Morris RE, Yatscoff RW, Ransom J, et al. Mycophenolate mofetil: a report of the consensus panel. Ther Drug Monit 1995;17(6):690-9.

[21] Saint-Marcoux F, Vandierdonck S, Prémaud A, Debord J, Rousseau A, Marquet P. Large scale analysis of routine dose adjustments of mycophenolate mofetil based on global exposure in renal transplant patients. Ther Drug Monit 2011;33(3):285-94.

[22] Rizopoulos D. JM: an R package for the Joint Modeling of Longitudinal and Time-toevent Data. J Stat Softw 2010;35:1-33.

[23] Tsiatis AA, Davidian M. Joint modeling of longitudinal and time-to-event data: an overview. Stat Sin 2004;14: 809-34.

[24] Yu M, Law NJ, Taylor JMG and Sandler HM. Joint longitudinal-survival-cure models and their application to prostate cancer. Stat Sin 2004;14: 835-62.

[25] Jacqmin-Gadda H, Thiébaut R, Dartigues J-F. Joint modeling of quantitative longitudinal data and censored survival time. Rev Epidemiol Sante Publique 2004;52(6):502-10. 
[26] Zhou Z, Shen J, Hong Y, Kaul S, Pfister M, Roy A. Time-varying belatacept exposure and its relationship to efficacy/safety responses in kidney-transplant recipients. Clin Pharmacol Ther 2012;92(2):251-7.

[27] Rizopoulos D. Dynamic predictions and prospective accuracy in joint models for longitudinal and time-to-event data. Biometrics 2011;67(3):819-29.

[28] Solez K, Colvin RB, Racusen LC, Haas M, Sis B, Mengel M, et al. Banff 07 classification of renal allograft pathology: updates and future directions. Am J Transplant 2008;8(4):753-60.

[29] Hougaard P. Fundamentals of survival data. Biometrics 1999;55(1):13-22.

[30] Rizopoulos D, Verbeke G, Molenberghs G. Multiple-imputation-based residuals and diagnostic plots for joint models of longitudinal and survival outcomes. Biometrics 2010;66(1):20-9.

[31] Pawinski T, Durlik M, Szlaska I, Urbanowicz A, Ostrowska J, Gralak B, et al. The weight of pharmacokinetic parameters for mycophenolic acid in prediction of rejection outcome: the receiver operating characteristic curve analysis. Transplant Proc 2006;38(1):86-9.

[32] Armstrong VW, Shipkova M, Schütz E, Weber L, Tönshoff B, Oellerich M. Monitoring of mycophenolic acid in pediatric renal transplant recipients. Transplant Proc 2001;33(12):1040-3.

[33] Shaw LM, Korecka M, Venkataramanan R, Goldberg L, Bloom R, Brayman KL. Mycophenolic acid pharmacodynamics and pharmacokinetics provide a basis for rational monitoring strategies. Am J Transplant 2003;3(5):534-42.

[34] Van Hest RM, Van Gelder T, Bouw R, Goggin T, Gordon R, Mamelok RD, et al. Timedependent clearance of mycophenolic acid in renal transplant recipients. Br J Clin Pharmacol 2007;63(6):741-52.

[35] Levy G, Thervet E, Lake J, Uchida K. Patient management by Neoral C(2) monitoring: an international consensus statement. Transplantation 2002;73(9 Suppl):S12-8.

[36] Cosio FG, Amer H, Grande JP, Larson TS, Stegall MD, Griffin MD. Comparison of low versus high tacrolimus levels in kidney transplantation: assessment of efficacy by protocol biopsies. Transplantation 2007;83(4):411-6.

[37] Webster AC, Woodroffe RC, Taylor RS, Chapman JR, Craig JC. Tacrolimus versus ciclosporin as primary immunosuppression for kidney transplant recipients: meta-analysis and meta-regression of randomised trial data. BMJ 2005;331:810-21.

[38] Lee Y-J, Kim B, Lee JE, Kim Y-G, Kim DJ, Kim S-J, et al. Randomized trial of cyclosporine and tacrolimus therapy with steroid withdrawal in living-donor renal transplantation: 5-year follow-up. Transpl Int $2010 ; 23(2): 147-54$. 
[39] Sandrini S, Aslam N, Tardanico R, Setti G, Bossini N, Valerio F, et al. Tacrolimus versus cyclosporine for early steroid withdrawal after renal transplantation. J Nephrol 2012;25(1):43-9.

[40] Van Gelder T, Silva HT, De Fijter H, Budde K, Kuypers D, Mamelok RD, et al. How delayed graft function impacts exposure to mycophenolic acid in patients after renal transplantation. Ther Drug Monit 2011;33(2):155-64.

[41] Karczewski J, Karczewski M, Wiktorowicz K. Preliminary study evaluating the risk factors of kidney acute rejection. Centr Eur J Immunol 2011; 36: 233-6.

[42] Woodle ES, Alloway RR, Buell JF, Alexander JW, Munda R, Roy-Chaudhury P, et al. Multivariate Analysis of Risk Factors for Acute Rejection in Early Corticosteroid Cessation Regimens Under Modern Immunosuppression. Am J Transplant 2005;5(11):2740-4.

[43] Gensburger O, Van Schaik RHN, Picard N, Le Meur Y, Rousseau A, Woillard J-B, et al. Polymorphisms in type I and II inosine monophosphate dehydrogenase genes and association with clinical outcome in patients on mycophenolate mofetil. Pharmacogenet Genomics 2010;20(9):537-43. 


\section{Figure Legends}

Figure 1: Distribution of mycophenolic acid area under the curve (AUC) values $(\boldsymbol{a})$ and MPA AUC/Dose ratios $(\boldsymbol{b})$ at the different post-transplantation follow-up periods (W: week, M: month). The line in the box is the median. The lower edge of the box represents the $25^{\text {th }}$ percentile and the upper edge the $75^{\text {th }}$ percentile. The dotted lines in the graph $(a)$ represent MPA exposure values of 30, 40 and $60 \mathrm{mg} \cdot \mathrm{h} / \mathrm{L}$ from bottom to top.

Figure 2: Flowchart of the modeling framework

Abbreviations: FD: fixed-dose group; CC: concentration-controlled group; AR: acute rejection; MPA AUC: mycophenolate acid inter-dose area under the plasma concentration $v s$. time curve.

Figure 3: Residual plots based on observed data for the final joint model in the training dataset. The top panels $(\boldsymbol{a})$ and $(\boldsymbol{b})$ depict the residual plots for the diagnostic fitting of the longitudinal sub-model, and the bottom panels $(\boldsymbol{c})$ and $(\boldsymbol{d})$ depict the residual plots for the diagnostic fitting of the survival sub-model. The superimposed lines in the three first plots $(\boldsymbol{a})$, (b) and (c) represent the fit of the loess smoother. In plot $(\boldsymbol{d})$, the solid lines represent the Kaplan-Meier estimates of the Cox-Snell residual for the event process, the dotted lines represent the $95 \%$ confidence interval of the Kaplan-Meier estimates and the superimposed bold line represents the unit exponential distribution of the survival function.

Figure 4: Distribution of MPA AUCs observed in patients exhibiting and not exhibiting acute rejection superimposed with the proposed ROC thresholds. 
The solid dark line represents the ROC thresholds obtained from model fit, and the dashed dark line represent a bootstrap-based $95 \%$ interval for these thresholds.

Figure $4 \mathrm{a}$ shows the mean area under the concentration time curve $\left(\mathrm{AUC}_{0-12 \mathrm{~h}}\right) \pm$ Standard Error of the Mean (-SEM-) calculated at 1 week, 2 weeks, 1, 3 and 6 months posttransplantation in patients who do not experience acute rejection. Figures $4 b, 4 c, 4 d$, and $4 \mathrm{e}$ show the individual MPA AUC profiles (including at least 2 AUC measurements) in patients who experienced AR in the first month, around 3 months, around 6 months, and after 6 months post-transplantation, respectively.

Figure 5: Typical examples of MPA AUC time-curves observed in patients who experienced AR: (a) patient with low MPA exposure(s) during the follow-up to the rejection and a MPA AUC higher than the proposed target at the time of diagnosis; (b) patient with a low MPA exposure at the time of diagnosis of $\mathrm{AR}$. 


\section{FIGURE 2}

DATA: $n=490$ kidney recipients

APOMYGRE : $F D: n=64 ; C C: n=64 ; 24$ AR episodes

OPERA : FD : $\mathrm{n}=104 ; \mathrm{CC}: \mathrm{n}=117 ; 16$ AR episodes

Routinely followed patients : FD : $n=108 ; C C: n=33 ; 15$ AR episodes

\section{Model development in 3 stages}

- Longitudinal submodel: a mixed-effect model to describe the MPA AUC time-course

- Survival submodel: a weibull survival model to describe the rejection-free survival

- Joint model: joint-modeling of the longitudinal mixed-effect model and the survival model

Model selection and evaluation

- Models were selected based on the Log-likelihood ratio test $(p<0.05)$

- Diagnostic plots were used to evaluate the goodness of fit of the selected joint model

\section{Internal model validation}

Bootstrap analysis was performed on the final joint model using 300 bootstrap samples

\section{Determination of time-dependent targets of MPA exposure}

Time dependent ROC curves adapted to the joint-models were used to determine MPA AUC thresholds minimizing the risk of AR 


\section{FIGURE 3}
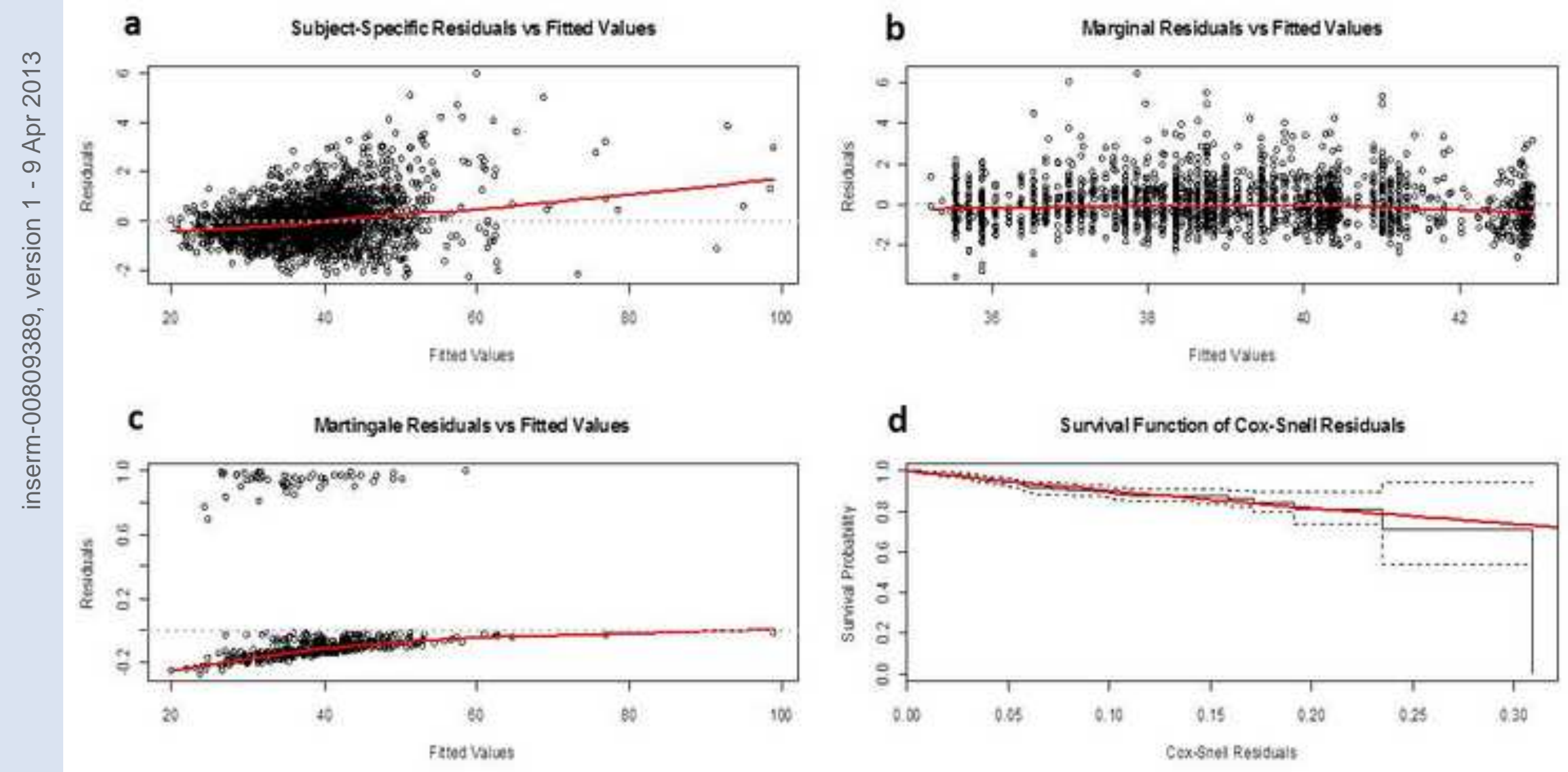


\section{FIGURE 4}

\section{a}

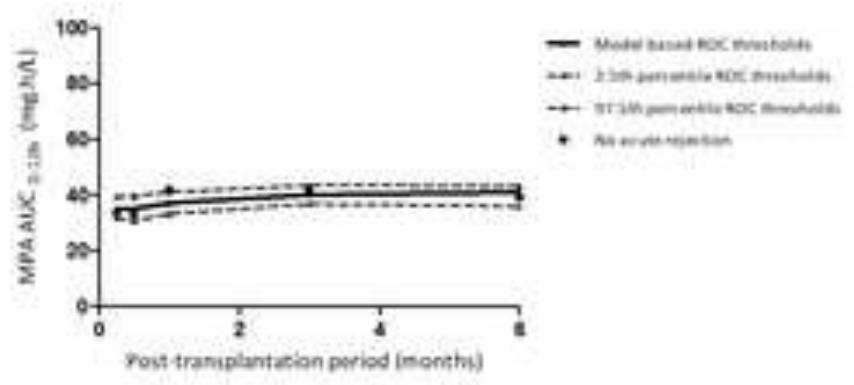

c

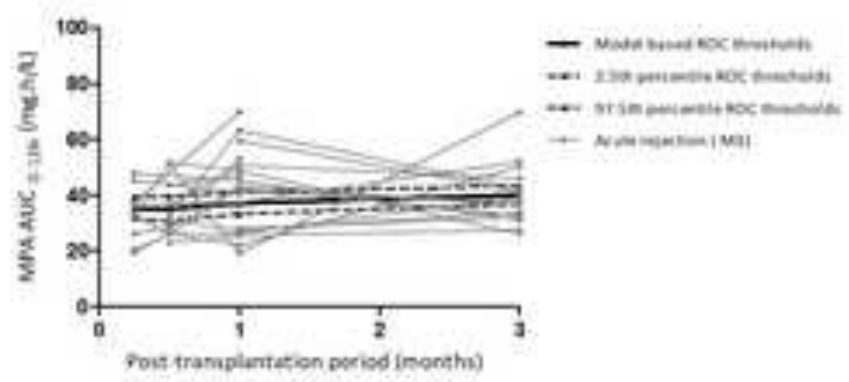

e

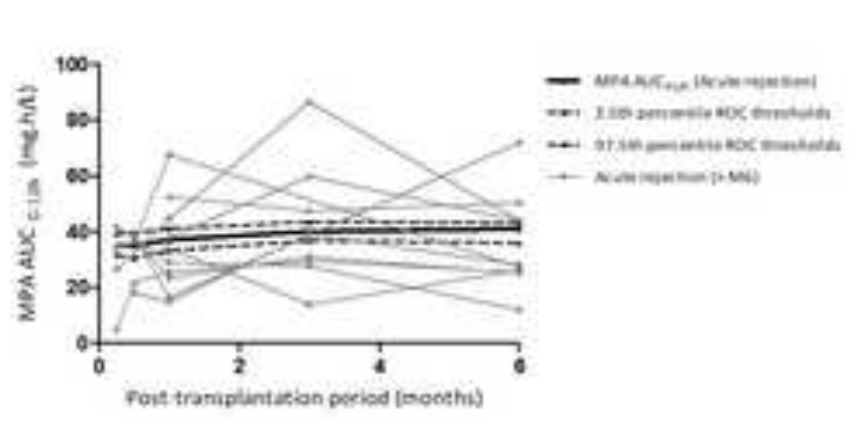

b

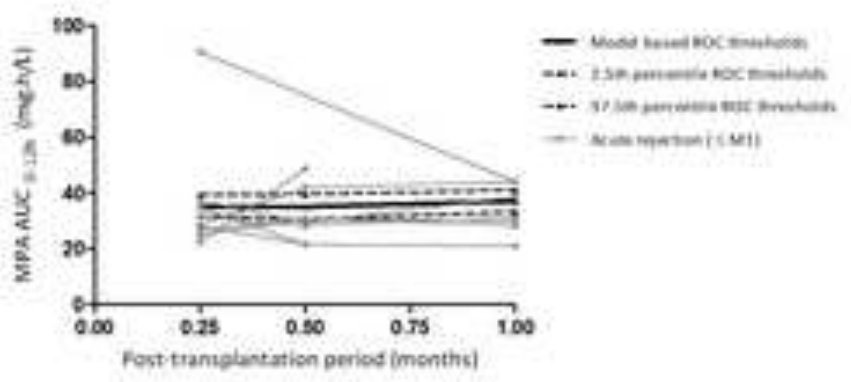

d

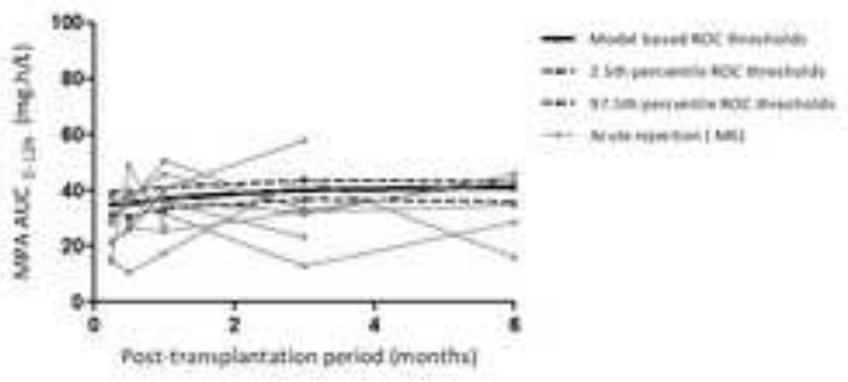

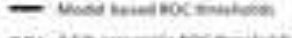

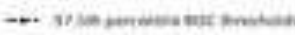

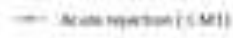




\section{FIGURE 5}

a

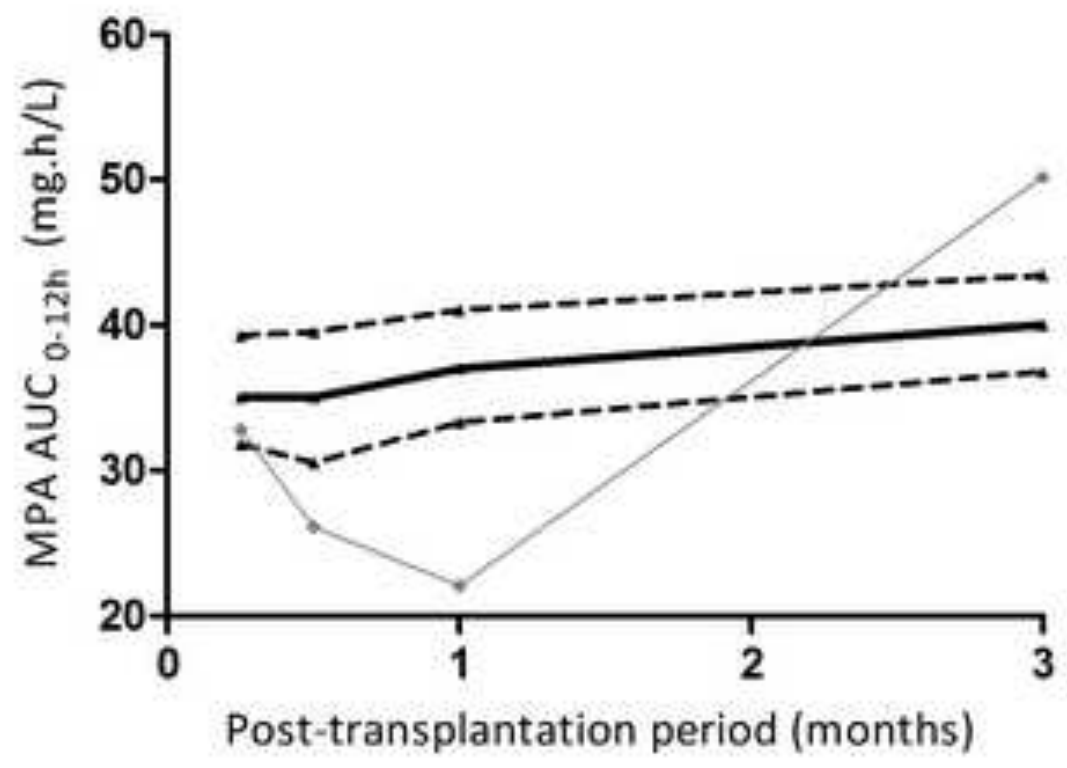

- Model based ROC thresholds

-m. 2,5th percentile ROC thresholds

--. 97.5 th percentile ROC thresholds

$\rightarrow$ Acute rejection (M3)

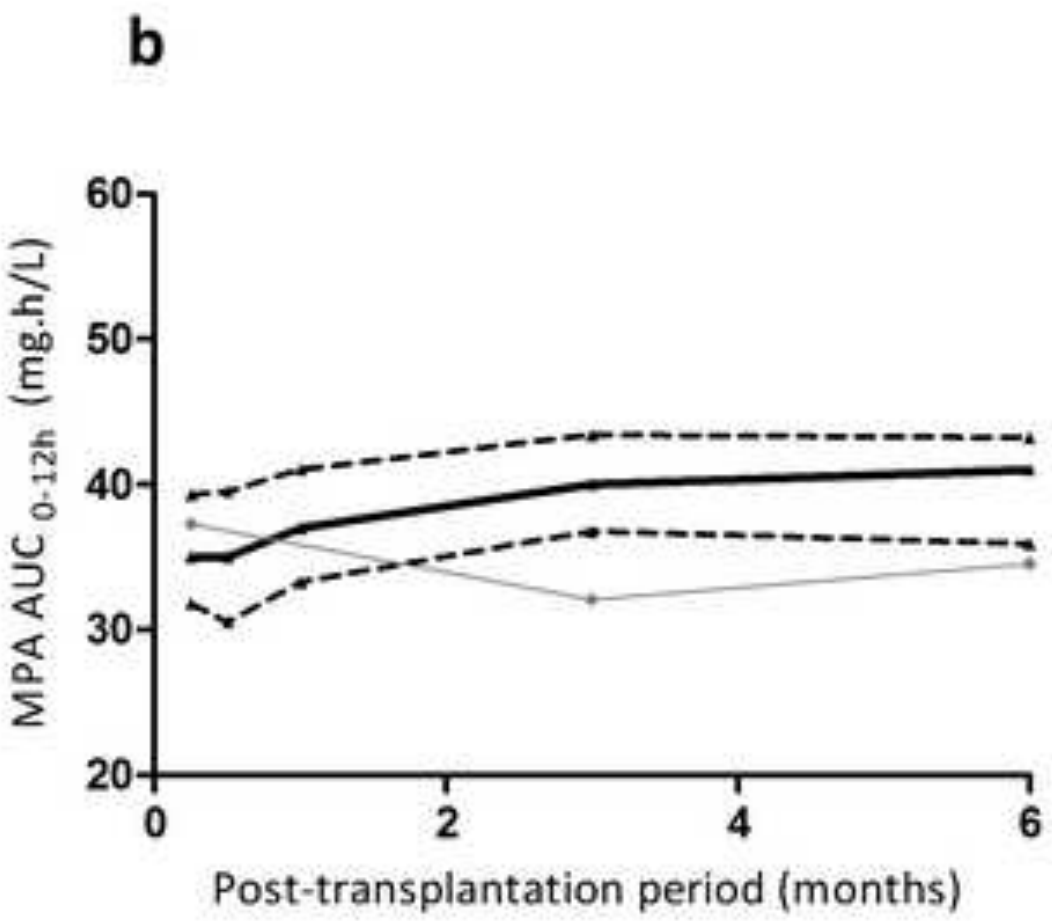

- Model based ROC thresholds

-m. 2.5 th percentile ROC thres holds

-m. 97.5 th percentile ROC thresholds

$\rightarrow$ Acute rejection (M6)

Post-transplantation period (months) 
Table 1. Demographic and clinical characteristics of the patients

\begin{tabular}{|c|c|c|c|c|}
\hline & APOMYGRE & OPERA & $\begin{array}{l}\text { Routinely } \\
\text { followed } \\
\text { patients }\end{array}$ & Total \\
\hline $\begin{array}{l}\text { Number of kidney } \\
\text { transplant recipients ( } \mathrm{n})\end{array}$ & 128 & 221 & 141 & 490 \\
\hline $\begin{array}{l}\text { Post-transplantation } \\
\text { follow-up time-points }\end{array}$ & $\begin{array}{l}\text { D7, D14, M1, } \\
\text { M3, M6, M12 }\end{array}$ & $\begin{array}{c}\text { D14, M1, M3, } \\
\text { M6, M12 }\end{array}$ & $\begin{array}{l}\text { D7, D14, M1, } \\
\text { M3, M6, M12 }\end{array}$ & - \\
\hline First transplantation (n) & 125 & 221 & 130 & 476 \\
\hline $\begin{array}{c}\text { Recipient age, } \\
\text { mean } \pm \text { SD (years) }\end{array}$ & $49.9 \pm 13.8$ & $48.3 \pm 13.0$ & $51.8 \pm 14.8$ & $\begin{array}{c}49.7 \\
\pm 13.8\end{array}$ \\
\hline $\begin{array}{l}\text { Acute rejection } \\
\text { episodes (n) }\end{array}$ & 24 & 16 & 15 & 55 \\
\hline $\begin{array}{l}\text { Time to diagnosis of acute } \\
\text { rejection, mean } \pm \text { SD } \\
\text { (days) }\end{array}$ & $114 \pm 109$ & $133 \pm 119$ & $158 \pm 111$ & $132 \pm 112$ \\
\hline $\begin{array}{l}\text { Dose-adjustment strategy } \\
\qquad(\mathrm{n}, \mathrm{FD} / \mathrm{CC})\end{array}$ & $64 / 64$ & $104 / 117$ & $108 / 33$ & $276 / 214$ \\
\hline
\end{tabular}

Abbreviations: D: day; M: month; SD: Standard Deviation; FD: fixed-dose group; CC: concentration-controlled group. 
Table 2. Immunosuppressive regimen as a function of patients' origin: the concentrationcontrolled (CC) and fixed-dose (FD) groups of the APOMYGRE and OPERA clinical trials, and the patients routinely followed at Limoges.

\begin{tabular}{|c|c|c|c|}
\hline Study & APOMYGRE & OPERA & Routinely followed patients* \\
\hline Induction therapy & basiliximab & basiliximab or daclizumab & basiliximab or thymoglobuline \\
\hline Maintenance therapy & $\begin{array}{l}-500 \mathrm{mg} \text { of i.v methylprednisolone } \\
\text { on day } 0 \text { followed by } 1 \mathrm{mg} / \mathrm{kg} / \mathrm{day} \\
\text { of prednisolone on days } 1-7,0.5 \\
\mathrm{mg} / \mathrm{kg} / \text { day on days } 8-14, \text { then } \\
\text { reduced weekly until discontinued } \\
\text { if possible }\end{array}$ & $\begin{array}{l}-500 \mathrm{mg} \text { of iv methylprednisolone on } \\
\text { day } 0 \text { followed by } 0.5 \mathrm{mg} / \mathrm{kg} / \text { day of } \\
\text { prednisolone until day } 7\end{array}$ & $\begin{array}{l}-500 \mathrm{mg} \text { of iv methylprednisolone } \\
\text { on day } 0 \text { followed by } 125 \mathrm{mg} \text { of } \\
\text { prednisolone on day } 1,20 \mathrm{mg} \text { on } \\
\text { days } 2-15 \text {, and then reduced } \\
\text { weekly until month } 3 .\end{array}$ \\
\hline 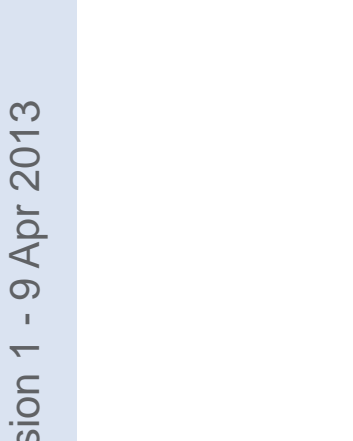 & $\begin{array}{l}-8+/-2 \mathrm{mg} / \mathrm{kg} / \text { day of cyclosporine } \\
\text { within } 3 \text { days post-transplant and } \\
\text { adjusted to maintain C2 levels of } \\
1300-1500 \mathrm{ng} / \mathrm{ml} \text { through week } 4 \text {, } \\
1100-1300 \mathrm{ng} / \mathrm{ml} \text { months } 2-3,900- \\
1100 \mathrm{ng} / \mathrm{ml} \text { months } 4-6 \text { and } 800 \\
\mathrm{ng} / \mathrm{ml} \text { months } 7-12\end{array}$ & $\begin{array}{l}\text {-cyclosporine was administered } \\
\text { within } 3 \text { days post-transplant with } \\
\text { the dose adjusted to maintain C2 } \\
\text { levels of } 1000-1500 \mathrm{ng} / \mathrm{ml} \text { through } \\
\text { week } 4,800-1200 \mathrm{ng} / \mathrm{ml} \text { weeks } 4-12 \text {, } \\
500-800 \mathrm{ng} / \mathrm{ml} \text { weeks } 12-52 \text {. }\end{array}$ & $\begin{array}{l}-0.15 \mathrm{mg} / \mathrm{kg} / \text { day of tacrolimus or } \\
5 \mathrm{mg} / \mathrm{kg} / \text { day of cyclosporine } \\
\text { within } 3 \text { days post-transplant. } \\
\mathrm{CSA} \mathrm{C2} \text { target levels were } 1000- \\
1500 \mathrm{ng} / \mathrm{ml} \text { through week } 4,800- \\
1200 \mathrm{ng} / \mathrm{ml} \text { weeks } 4-12,500-800 \\
\mathrm{ng} / \mathrm{ml} \text { weeks } 12-52 \text {. } \\
\text { Tacrolimus trough levels were 8- } \\
12 \mathrm{ng} / \mathrm{mL} \text { through week } 4 \text { then 6- } \\
8 \mathrm{ng} / \mathrm{mL} \text {. }\end{array}$ \\
\hline 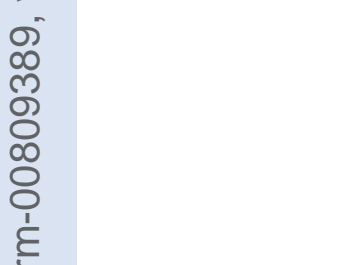 & $\begin{array}{l}\text { - } 1 \mathrm{~g} \text { twice daily of MMF in the FD } \\
\text { group, and } 1 \mathrm{~g} \text { twice daily of MMF } \\
\text { in the CC group until day } 7 \text { and } \\
\text { then adjusted to reach an MPA } \\
\text { AUC target of } 40 \mathrm{mg} \cdot \mathrm{h} / \mathrm{L}\end{array}$ & $\begin{array}{l}\text { - } 1 \mathrm{~g} \text { twice daily of MMF in the FD } \\
\text { group, and } 3 \mathrm{~g} / \text { day of MMF in the CC } \\
\text { group until day } 10 \text { and then adjusted } \\
\text { to a target MPA AUC of } 40 \mathrm{mg} . \mathrm{h} / \mathrm{L} \text {. }\end{array}$ & $\begin{array}{l}\text { - } 1 \mathrm{~g} \text { twice daily of MMF in the FD } \\
\text { group, and } 1 \mathrm{~g} \text { twice daily of MMF } \\
\text { in the CC group and then } \\
\text { adjusted in the first week to } \\
\text { reach an MPA AUC target } \\
\text { between } 30 \text { and } 60 \mathrm{mg} . \mathrm{h} / \mathrm{L} \text {. }\end{array}$ \\
\hline
\end{tabular}

Abbreviations: D: day; M: month; MMF: mycophenolate mofetil; MPA AUC: mycophenolate acid inter-dose area under the plasma concentration vs. time curve; C2 CSA: cyclosporine (CSA) $2 \mathrm{~h}$ post-dose (C2).

*These patients were not enrolled in any kind of concentration-controlled clinical trial; their MPA AUCs were estimated using our ISBA website (https://pharmaco.chu-limoges.fr). 
Table 3. The parameter estimates and bootstrap results of the final joint model.

\begin{tabular}{|c|c|c|c|c|c|}
\hline & \multirow{3}{*}{ Parameters } & \multicolumn{2}{|c|}{ Final model results } & \multirow{2}{*}{\multicolumn{2}{|c|}{$\begin{array}{l}\text { Bootstrap results } \\
\text { (n=300 samples) }\end{array}$}} \\
\hline & & & & & \\
\hline & & Estimates (se) & $P$ value & Mean estimates & $95 \% \mathrm{Cl}$ \\
\hline \multirow{4}{*}{$\begin{array}{l}\text { Longitudinal } \\
\text { sub-model }\end{array}$} & $\beta_{0}$ (Intercept) & $33.6(0.8)$ & $<0.001$ & 37.6 & $37.5 ; 37.7$ \\
\hline & $\beta_{1}$ (Time) & $18.2(3.4)$ & $<0.001$ & 17.9 & $17.7 ; 18.2$ \\
\hline & $\beta_{2}$ (Time $\times$ Time) & -15.7 (3.4) & $<0.001$ & -15.2 & $-15.4 ;-15.1$ \\
\hline & $\beta_{3}(\mathrm{DA})$ & $-2.5(1.0)$ & 0.0187 & -2.4 & $-2.5 ;-2.3$ \\
\hline \multirow{4}{*}{$\begin{array}{l}\text { Survival } \\
\text { sub-model }\end{array}$} & $\gamma$ (Age) & $-0.0088(0.01)$ & 0.4025 & -0.012 & $-0.016 ;-0.0081$ \\
\hline & $\alpha($ MPA AUC (t)) & $-0.044(0.017)$ & 0.0081 & -0.053 & $-0.055 ;-0.051$ \\
\hline & *Intercept & $0.13(0.83)$ & 0.8733 & 0.39 & $0.32 ; 0.45$ \\
\hline & *Log(scale) & $-0.19(0.12)$ & 0.1264 & -0.17 & $-0.19 ;-0.16$ \\
\hline \multirow{7}{*}{$\begin{array}{c}\text { Variance } \\
\text { Components }\end{array}$} & D0 & 8.3 & - & 7.9 & $7.8 ; 8.1$ \\
\hline & D1 & 6.6 & - & 7.2 & $7.0 ; 7.4$ \\
\hline & D2 & 11.8 & & 12.0 & $11.8 ; 12.2$ \\
\hline & D01 & -0.39 & - & -0.38 & $-0.40 ;-0.35$ \\
\hline & D02 & -0.49 & - & -0.48 & $-0.50 ;-0.46$ \\
\hline & D12 & 0.11 & - & 0.12 & $0.094 ; 0.14$ \\
\hline & ? & 14.2 & _ & 14.1 & $14.0 ; 14.2$ \\
\hline
\end{tabular}

N.B. $\beta_{0}, \beta_{1}, \beta_{2}$, and $\beta_{3}$ represent the mean regression coefficients of the longitudinal sub-model. $\gamma_{1}, \gamma_{2}$, and $\alpha$ represent the mean regression coefficients of the survival sub-model. D0 denotes the variance of the random intercept, D1 the variance of the random linear term of time effect, D2 the variance of the effect due to the dose-adjustment strategy; and D01, D02 and D12 their covariances. $\varepsilon$ denotes the residual error corresponding to the measurement errors. $\left({ }^{*}\right)$ Intercept and log scale are the two parameters defining the Weibull baseline function (ho(t)).

se: standard error; $\mathrm{Cl}$ : confidence intervals; DA: dose-adjustment strategy, MPA AUC(t): mycophenolate acid inter-dose area under the plasma concentration vs. time curve. 


\section{Supplementary Material and Methods}

The joint model framework used in this study has been described by Rizopoulos et al (1) and can be formulated briefly in the following 3 steps:

\section{- The longitudinal sub-model}

The "true unobserved" (i.e., theoretical) trajectory of the biomarker is described by a mixedeffects model which can be expressed as:

$$
\begin{aligned}
Y_{i}(t) \mid b_{i} & =m_{i}(t)+\varepsilon_{i}(t) \\
& =\mathbf{x}_{i}^{\mathbf{T}}(t) \beta+\mathbf{z}_{i}^{\mathbf{T}}(t) b_{i}+\varepsilon_{i}(t), \quad \varepsilon_{i}(t) \sim N\left(0, \sigma^{2}\right)
\end{aligned}
$$

Where :

$\mathrm{Y}_{\mathrm{i}}(\mathrm{t})$ denotes the observed available measurements of the biomarker at time point $\mathrm{t}$ for the $i^{\text {th }}$ subject

$\mathrm{x}_{\mathrm{i}}(\mathrm{t})$ and $\beta$ represents the mean response (i.e., fixed effect), with $\mathrm{x}_{\mathrm{i}}$ the explanatory variable and $\beta$ its corresponding regression coefficient.

$z_{i}(t)$ and $b_{i}$ represents the subject-specific variability (i.e., random effect), with $z_{i}(t)$ the random variables and $b_{i}$ their corresponding coefficient, $b_{i}(t) \sim N(0, D)$.

$>\varepsilon_{\mathrm{i}}(\mathrm{t})$ is the measurement error of the longitudinal outcome, with variance $\sigma^{2}$

Basically, in the mixed-effects model, all the individual profiles are described using the same mathematical equation (i.e., fixed effects), but due to the inter-patient variability (i.e., random effects), the coefficient values used in the equation are different for each patient, allowing thereby for different patient-specific profiles in time.

\section{- The survival sub-model}

The survival sub-model is described as a time-dependent relative risk model using a baseline risk function:

$$
\mathrm{h}_{\mathrm{i}}\left(\mathrm{t} \mid \mathrm{M}_{\mathrm{i}}(\mathrm{t})\right)=\mathrm{h}_{0}(\mathrm{t}) \exp \left\{\gamma^{\mathrm{T}} \mathrm{w}_{\mathrm{i}}+\boldsymbol{\alpha} \mathrm{m}_{\mathrm{i}}(\mathrm{t})\right\}
$$


Where:

$\mathrm{h}_{0}(\mathrm{t})$ is the baseline risk function. Several different options including both parametric (i.e., Weibull, piecewise-constant, B-splines) or semi-parametric (i.e., Cox) models are available for $\mathrm{h}_{0}(\mathrm{t})$ in the JM package.

$\mathrm{M}_{\mathrm{i}}(\mathrm{t})=\left\{\mathrm{m}_{\mathrm{i}}(\mathrm{s}), 0 \leq \mathrm{s}<\mathrm{t}\right\}$ denotes the theoretical, unobserved biomarker history up to time $\mathrm{t}$. The true trajectory of the biomarker at time $\mathrm{t}\left(\mathrm{m}_{\mathrm{i}}(\mathrm{t})\right)$ is obtained using the mixedeffects longitudinal sub-model described above.

$\alpha$ quantifies the effect of the biomarker on the hazard for the event. It measures the strength of the association between $\mathrm{m}_{\mathrm{i}}(\mathrm{t})$ that denotes the true level of the biomarker at time $t$, and the hazard for an event at the same time point.

$\mathrm{W}_{\mathrm{i}}$ is a vector of baseline covariates (such as a treatment indicator, age ...) with a corresponding vector of regression coefficients $\gamma$.

\section{- The joint model}

The two processes (survival sub-model and longitudinal sub-model) are combined using joint log-likelihood estimation. This joint distribution between the two processes assumes that both sub-models share the same random effects (conditional independence assumptions).

In order to fit the joint model, the objects returned by the mixed-effects sub-model and the survival sub-model were used as the main arguments in the joint model, also called "time to event model". The Gauss Hermite integration rule was used for the maximization of the joint log-likelihood function.

(1) Rizopoulos, D. JM: an R package for the Joint Modeling of Longitudinal and Time-toevent Data. J. Stat. Softw. 35, 1-33 (2010). 


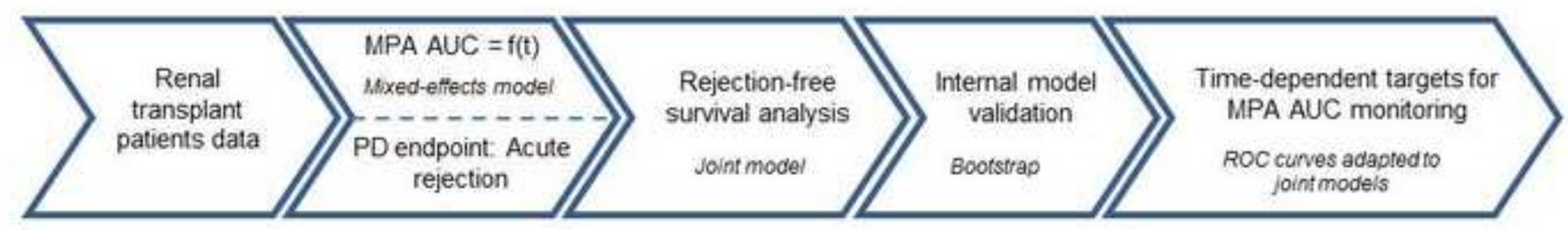

